\title{
Key Factors Influencing Multimodal Transportation of Natural Block Rubber in Thailand
}

\author{
Pimnapa Pongsayaporn ${ }^{1 *}$, Thanwadee Chinda $^{1}$, Veeris A mmarapala ${ }^{1}$ \\ ${ }^{1}$ School of M anagement Technology, Sirindhorn International Institute of Technology, Thammasat \\ University, 131 M 005 Tiwanont Rd. B angkadi, M uang, Pathumthani 12000 Thailand,
}

\begin{abstract}
Thailand is the world's largest natural rubbers exporter. The major type of natural rubbers exported is block rubber. Currently, the transportation of natural rubbers in Thailand depends mainly on truck mode because of the convenience and extensive netw ork of roads. However, Thailand confronts road transportation limitations including maximum acceptable weight, traffic congestion and high fuel prices. Dealing with these problems, the multimodal connection from roads to container yards (CY) and ports is expected to decrease logistics cost, and increase various opportunities to trade with neighbouring countries. This paper, thus, aims at examining key factors influencing the use of multimodal transportation utilizing the exploratory factor analysis (EFA). The principal components analysis (PCA) method, together with the eigenvalue over 1 , factor loading of 0.40 , and varimax rotation method, extracted five key factors with a total of 20 associated attributes, which are the Multimodal Operation, Service Operation, Multimodal Service Provider, M arket Consideration, and Road Constraints factors. The result also pinpoints the capacity of container yard $(C Y)$ or port, accessibility to container yard $(C Y)$ or port, documentation process, logistics cost, adequacy of a multimode service provider, and law enforcement on truck driving hours, as crucial attributes in planning for multimodal transportation. This paper can be used as a guideline for a feasibility study of multimodal transportation of natural block rubber in Thailand.
\end{abstract}

Keywords: factor analysis, key factors, logistics, multimodal transportation, natural block rubber

\section{Introduction}

Thailand is a major supplier of agricultural products in the world [1]. It is the world's leading exporter of natural rubbers, rice, and cassava [2]. In particular, Thailand is the largest producer and exporter of natural rubbers due to its tropical climate as well as effective and advanced cultivation methods [3]. Nearly $90 \%$ of Thailand's natural rubber production is for export and only $10 \%$ is used for domestic consumption [4]. The major type of natural rubbers

* Corresponding author: meiw.pimnapa@gmail.com 
exported is block rubber. It takes more than one-third of the total amount and still increases with $4.5 \%$ growth rate because they are mainly used in automobile tires manufacturing in China, which is the biggest importer of black rubber from Thailand [4].

Currently, the transportation of block rubber in Thailand depends mainly on truck mode because of the convenience and extensive network of roads. However, the logistics cost of road transportation is higher than rail and ship modes. Moreover, Thailand confronts road transportation limitations including maximum acceptable weight, traffic congestion and high fuel prices [5]. Dealing with these problems, the multimodal connection from roads to container yards (CY) and ports is expected to decrease logistics cost, and increase various opportunities to trade with neighbouring countries [6]. According to Muller [7], the multimodal transportation is the combination of two or more modes of movement of goods, such as road, rail, or sea under the control or ownership of one operator. It is also termed 'intermodal transportation', all of which function in exactly the same way [8].

In recent years, there are a number of initiatives of modal shifts proposed by the government. It realizes the importance of inland transportation connecting with the export gateways. Thus, it proposes the "Thailand's Transport Infrastructure Development Strategy 2015-2022" [9] to develop the efficient transportation network for being a regional hub. This plan aims to enhance the efficiency of multimodal transportation and reduce logistics cost. The plan includes two main parts; the double-track railway project for improving the transportation network and the development of ports to support the increasing amount of export products.

In general, block rubber has a low price and low value [5]. The most effective transportation mode for block rubber is the mode that can carry them in large volume [5] which is the characteristics of multimodal transportation. According to Tanachodrungsatis [10], multimodal transportation is suited with products that can be transported in a heavy bulk and products that have low value, the low selling price per unit, and not perishable. In this respect, the objective of this paper is to examine key factors influencing the use of multimodal transportation for block rubber transportation utilizing the exploratory factor analysis (EFA). It is expected that private companies and government could use the study results as a guideline for a feasibility study of multimodal transportation of block rubber in Thailand. The research steps are summarized, as shown in Figure 1.

Activities

Outputs

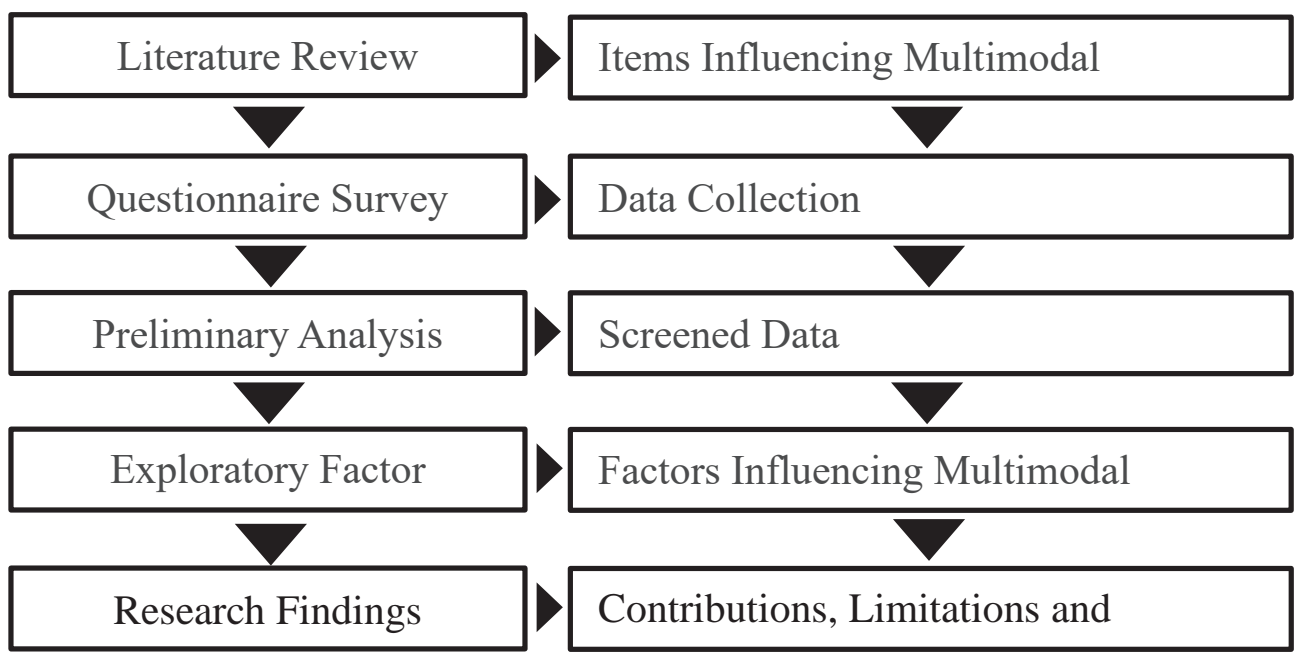

Fig. 1. Research Steps 


\section{Items Influencing Multimodal Transportation}

A total of 20 items influencing multimodal transportation were extracted, with reference to the citation frequency in the recent multimodal transportation-related previous studies (see Table 1). These items were used in the questionnaire survey development to measure the opinions or experiences of respondents on each item.

Table 1. Items Influencing Multimodal Transportation

\begin{tabular}{lll}
\hline No. & \multicolumn{1}{c}{ Item } & References \\
\hline 1 & Government Policy & {$[11,12]$} \\
2 & Road Traffic Congestion & {$[8,11]$} \\
3 & Law Enforcement on Truck Driving Hours & {$[13,14]$} \\
4 & Road Accident & {$[14,15]$} \\
5 & Adequacy of Multimode Service Providers & {$[16,17]$} \\
6 & Company and Service Provider Relationship & {$[18,19]$} \\
7 & Punctuality & {$[16,20]$} \\
8 & Delivery Speed & {$[14,21]$} \\
9 & Accessibility of CY or Port & {$[13]$} \\
10 & Capacity of CY or Port & {$[13]$} \\
11 & Transshipment Equipment & {$[11]$} \\
12 & Transhipment Cost & {$[8]$} \\
13 & Tracking System & {$[19,20]$} \\
14 & Volume Flexibility & {$[14,22]$} \\
15 & Multimodal Equipment Design & {$[14,20]$} \\
16 & Logistics Cost & {$[13]$} \\
17 & Green Image & {$[14,15]$} \\
18 & Market Competitiveness & {$[8]$} \\
19 & Skilled Employee & {$[19]$} \\
20 & Documentation Process & {$[13,19]$} \\
\hline & &
\end{tabular}

\section{Questionnaire Survey and Data Screening}

\subsection{Questionnaire Survey Development}

To gain information from the rubber production companies and transportation service providers, a questionnaire was designed and distributed through face-to-face interviewing, mail, online survey and e-mail. In this study, the questionnaire survey was developed to extract factors influencing multimodal transportation of natural block rubber in Thailand utilizing EFA. The questionnaire survey comprised three parts. Part I considered the information of the respondent and company. Part II consisted of 20 statements related to items influencing multimodal transportation. A 5-point Likert scale was used to rate the level of agreement on each statement based on respondents' experience, from $1=$ strongly disagree to $5=$ strongly agree. An example of statements in Part II is presented in Table 2. Part III was the open-ended question requesting qualitative data regarding suggestion or comment about issues related to the multimodal transportation based on respondents' experience. 
Table 2. Sample of Questionnaire Survey Questions

\begin{tabular}{llllll}
\hline \multirow{2}{*}{ NO. } & \multicolumn{1}{c}{ Statement } & \multicolumn{3}{c}{ Level } \\
\cline { 3 - 5 } & & $\mathbf{1}$ & $\mathbf{3}$ & $\mathbf{4}$ & $\mathbf{5}$ \\
\hline 1 & Government policy supporting multimodal transportation & & & & \\
2 & Road traffic congestion & & & \\
3 & Law enforcement on truck driving hours & & & \\
4 & Accident occurrence during road transportation & & \\
5 & $\begin{array}{l}\text { Adequacy of multimodal transportation service providers } \\
6\end{array}$ & $\begin{array}{l}\text { Good relationship between company and transportation service } \\
\text { providers }\end{array}$ & & \\
\end{tabular}

Note: Please indicate the level of your agreement on each statement based on your experience using the scale from 1 to 5 , for which $1=$ strongly disagree and $5=$ strongly agree.

\subsection{Survey Responses}

A total of 1,411 questionnaires were distributed to medium and large rubber production companies and transportation service providers located in the north-eastern and the southern parts of Thailand. There were 159 returns of the questionnaire, representing an $11.27 \%$ response rate. In this respect, all 159 questionnaires were used for further analyses.

It was found that all respondents were in managerial or senior positions in their organizations, and the majority of the respondents $(69 \%)$ has been working in rubber production industry or transportation service industry for at least 5 years. This implied that the respondents had strong practical experience and were competent enough in providing reliable responses. Moreover, most of the companies (60\%) have been exporting their products through Laem Chabang port with partially using multimodal transportation. This implied the possibility of enhancing the use of multimodal transportation in their companies. In summary, these results prove the credential and suitability of the respondents in providing data for the analysis.

\subsection{Preliminary Analysis}

The collected data were then screened to confirm its level of confidence. The study applied two statistical methods, including the normality test and outlier test. The normality in distribution was tested by examining skewness and kurtosis before conducting an EFA [23]. Skewness measures asymmetry of a distribution of a variable. The skew value of a normal distribution is zero. A skewed variable is a variable whose mean is not in the centre of the distribution. Kurtosis, on the other hand, measures a peakedness of the distribution [24]. Garson [25] proposed a reference of substantial departure from normality as an absolute skew value $>2$ and kurtosis value $>7$. In this respect, the absolute values of skewness $<2$ and kurtosis $<7$ are acceptable. The results showed that the data of all 20 attributes were normally distributed, thus, increasing the confidence for factor analysis.

The 5\% trimmed mean and standardized scores ( $\mathrm{z}$ - scores) were used to detect outliers in this study. The 5\% trimmed mean is a mean calculated by discarding a $5 \%$ of the lowest and the highest scores and then computing the mean of the remaining scores. If a difference between mean and 5\% trimmed mean is not beyond the criteria of 0.20 , it demonstrated an insignificant influence of any possible outliers within the data. The results showed that there was no outlier in the collected data. To confirm the use of 5\% trimmed mean method, the influence and presence of outliers was assessed by standardized scores ( $\mathrm{z}$ - scores) for each case. A case was considered to be a potential outlier if its absolute standardized residual 
was greater than 3.29 at $\mathrm{p}<0.01$, two-tailed test [26]. The results also showed the absence of outlier in this study. Therefore, it can be confirmed that the 159 sets of data were suitable for the EFA.

\section{Exploratory Factor Analysis (EFA)}

Before performing the EFA, the 20 items were categorized into three groups, which are 'operation', 'market', and 'road constraints' (see figure 2). Cronbach's alpha test was then performed as a measure of the reliability of each group [27]. According to De Vellis [28], a minimum of Cronbach's alpha value of 0.70 is considered to be reliable. The results showed that all groups had $\alpha$ values ranging from 0.81 to 0.83 , thus confirming the reliability of all groups.

The Kaiser-Meyer-Olkin (KMO) and Bartlett's test of sphericity were then conducted to determine if the data was suitable for EFA, and to confirm that the data had patterned relationships [29] By theory, the minimum acceptable value of $\mathrm{KMO}$ is 0.60 [30] and Bartlett's Test of Sphericity should be significant $(p<0.05)$. KMO values of all three groups were $0.78,0.77$, and 0.71 , respectively, and all of them were significant at $p<0.05$. The results confirmed that all groups were suitable for applying the EFA method.

\begin{tabular}{|c|}
\hline 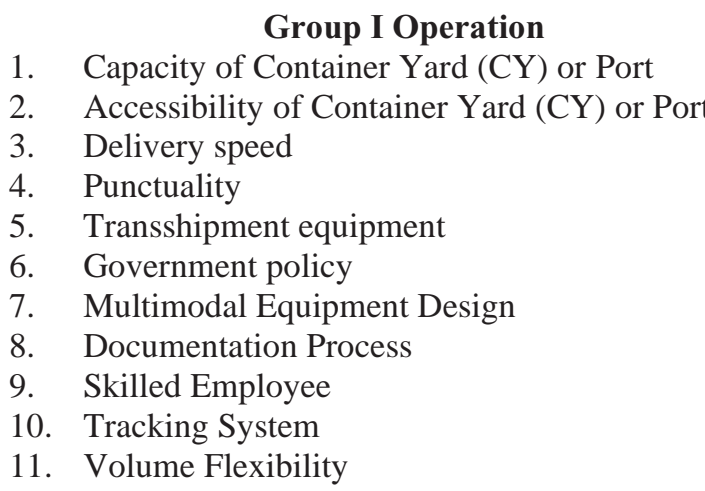 \\
\hline $\begin{array}{l}\text { Group II Market } \\
\text { 12. A dequacy of M ultimode Service Providers } \\
\text { 13. Company and Service Provider Relationship } \\
\text { 14. Green image } \\
\text { 15. Logistics Cost } \\
\text { 16. M arket Competitiveness } \\
\text { 17. Transshipment cost }\end{array}$ \\
\hline $\begin{array}{l}\text { Group III Road Constraints } \\
\text { 18. Law Enforcement on Truck D riving Hours } \\
\text { 19. Road Traffic Congestion } \\
\text { 20. Road Accident }\end{array}$ \\
\hline
\end{tabular}

Fig. 2. Three Groups of 20 I tems 
Each group was then analyzed with the EFA method to determine how items are interrelated [31] and to reduce the number of items into a smaller number of factors [33]. In this study, a principal component analysis (PCA) extraction method together with the eigenvalue over 1 , a cut-off factor loading of 0.40 , and varimax rotation method were applied to examine the dimensionality of items in each group [33]. The EFA results classified 20 items into five key factors, accounting for the total variance for each group of $55.75 \%$, $62.66 \%$, and $72.55 \%$, respectively (see table 3 ). All five key factors had $\alpha$ values ranging from 0.75 to 0.84 , thus confirming the reliability of the five factors.

Table 3. EFA Results

\begin{tabular}{|c|c|c|c|c|c|}
\hline \multirow{3}{*}{ Items } & \multicolumn{2}{|c|}{ Group I } & \multicolumn{2}{|c|}{ Group II } & \multirow{3}{*}{$\frac{\mathrm{p} \mathrm{III}^{\text {Grou }}}{\mathrm{rV}^{\text {Facto }}}$} \\
\hline & \multirow{2}{*}{$\begin{array}{l}\text { Fact } \\
\text { or I }\end{array}$} & \multirow{2}{*}{$\begin{array}{l}\text { Fact } \\
\text { or II }\end{array}$} & \multirow{2}{*}{$\begin{array}{l}\text { Fact } \\
\text { or III }\end{array}$} & \multirow{2}{*}{$\begin{array}{l}\text { Fact } \\
\text { or IV }\end{array}$} & \\
\hline & & & & & \\
\hline Capacity of Container Yard & 0.82 & & & & \\
\hline$(\mathrm{CY})$ or Port & & & & & \\
\hline Accessibility of Container & 0.82 & & & & \\
\hline Yard (CY) or Port & & & & & \\
\hline Delivery Speed & 0.79 & & & & \\
\hline Punctuality & 0.75 & & & & \\
\hline Transshipment Equipment & 0.74 & & & & \\
\hline Multimodal Equipment & 0.49 & & & & \\
\hline Design & & & & & \\
\hline Government Policy & 0.46 & & & & \\
\hline Volume Flexibility & 0.42 & & & & \\
\hline Documentation Process & & 0.85 & & & \\
\hline Skilled Employee & & 0.81 & & & \\
\hline Tracking System & & 0.75 & & & \\
\hline Logistics Cost & & & 0.84 & & \\
\hline Green Image & & & 0.82 & & \\
\hline Market Competitiveness & & & 0.81 & & \\
\hline Transhipment Cost & & & 0.63 & & \\
\hline Adequacy of Multimode & & & & 0.87 & \\
\hline Service Providers & & & & & \\
\hline Company and Service & & & & 0.84 & \\
\hline Provider Relationship & & & & & \\
\hline Law Enforcement on Truck & & & & & 0.87 \\
\hline Driving Hours & & & & & \\
\hline Road Traffic Congestion & & & & & 0.85 \\
\hline Road Accident & & & & & 0.83 \\
\hline
\end{tabular}

Note:

Factor I was named as 'Multimodal Operation Factor'

Factor II was named as 'Service Operation Factor'

Factor III was named as 'Market Consideration Factor'

Factor IV was named as 'Multimodal Service Provider Factor'

Factor V was named as 'Road Constraints Factor' 


\section{Conclusion}

Currently, natural rubber transportation in Thailand depends mainly on truck mode. The road transportation limitations include maximum acceptable weight, traffic congestion, high accident occurrence and high fuel prices. The implementation of multimodal transportation would help alleviate these problems and environmental effects. It also helps maximize the effectiveness of transportation because it can carry more quantity of goods while helping save energy and save logistics cost.

The study results revealed five key factors influencing the multimodal transportation of natural block rubber in Thailand, including Multimodal Operation, Service Operation, Multimodal Service Provider, Market Consideration, and Road Constraints factors. These factors can be used as a guideline for a feasibility study of multimodal transportation of natural block rubber in Thailand. The capacity of container yard (CY) or port, accessibility to container yard (CY) or port, documentation process, logistics cost, adequacy of the multimode service provider, and law enforcement on truck driving hours are found to be the most important variables for successful implementation of multimodal transportation.

The survey has been limited to a sample of rubber production companies and transportation service providers in north-eastern and the southern parts of Thailand because they are the growing area of the government plan and the heart of rubber plantation and production in Thailand, respectively. The results, however, provided a useful fundamental data in order to increase the use of multimodal transportation.

The 20 items were grouped to explain five latent factors which lead to a baseline model for further examination of interrelationships among them by using structural equation modelling.

\section{References}

1. P. L uathep, S. J aensirisak, S. Saengpradab, The impact of transport infrastructure development on modal shift: case study of rubber goods in the southern Thailand, $K K U$ Engineering Journal, 43: 225-227 (2016)

2. USDA, Thailand Exporter Guide, U nited States Department of A griculture (2017)

3. BOI, Thailand's Rubber Industry, B angkok: Thailand B oard of Investment (2017)

4. CPD, Direction of Thai Rubber Industry in the ASEAN (in Thai), Bangkok: Cooperative Promotion D epartment (2015)

5. W. Timaboot, N. Suthikarnnarunai, Designing the Distribution N etwork in a Cassava Supply Chain in Thailand, Marketing and Branding Research, 4, 206-216 (2017)

6. B. Polyiam, The Study of Cost and Time of Rice Transportation: Export Route from Nakhonsawan (in Thai), The 9th Logistics and Supply Chain Conference (ThaiVCML2009), Thailand, 2009.

7. G. M uller, Intermodal Freight Transportation (3rd ed.). W estport, Connecticut: Eno Transportation Foundation (1995)

8. M. SteadieSeifi, N.P. D ellaert, W. N uijten, T. V an W oensel, R. Raouf, M ultimodal Freight Transportation Planning: A Literature R eview. European Journal of Operational Research, 233:1-15 (2013)

9. Thai government, Thailand's Transport Infrastructure Development Strategy 2015 2022, B angkok: Thai government (2015) 
10. K. Tanachodrungsatis, Efficiency and Effectiveness of Thai Rice Transportation L ogistic: A Case Study Transportation Route from Nakornsawan Province to Foreign Countries, Suthiparithat Journal, 28: 309-342 (2014)

11. B.L. Choi, K.Y. Chung, K.D., Lee, The impact of policy measures on promoting the modal shift from road to rail, Personal and Ubiquitous Computing, 18: 1423-1429 (2014)

12. F. Corman, F. Viti, R.R. Negenborn, Equilibrium models in multimodal container transport systems, Flexible Services and Manufacturing Journal, 29:125-153 (2017)

13. D. K ritchanchai, W. Chanpuypetch, A Framework for Decision Support Systems in Logistics: A Case Study for Thailand Rubber Exports, International Journal of Logistics and SCM Systems, 3(1): 24-31 (2009)

14. M. Heljedal, Factors Influencing the Choice between Road and Multimodal Transportation, Thesis (Master), Linköping University, Sweden (2013)

15. E. K reutzberger, C. M acharis, L. V ereecken, J. W oxenius, Is Intermodal Freight Transport M ore Environmentally Friendly Than All-R oad Freight Transport? A Review, NECTAR Conference No 7, 13-15 June, 2003, Umeå, Sweden (2003)

16. T. B ektas, T.G. Crainic, A Brief Overview of Intermodal Transportation. Canada: Interuniversity Research Centre on Enterprise N etworks, Logistics and Transportation (2007)

17. K. Roberts, Key Factors and Trends in Transportation M ode and Carrier Selection, Pursuit - The Journal of Undergraduate Research at the University of Tennessee, 4(1): 40-52 (2012)

18. A.C. Paixao-Casaca, P.B. M arlow, Logistics strategies for short sea shipping operating as part of multi-modal transport chain, Maritime Policy and Management, 36(I): 1-19 (2009)

19. T.L. B utta, M .B. A begaz, Challenges in the operation of multimodal transport system: The case of Ethiopian shipping and logistics services enterprise, International Journal of Applied Research, 2(7): 927-932 (2016)

20. D.M. Islam, S. Ricci, B.L. N elldal, How to make modal shift from road to rail possible in the European transport market, as aspired to in the EU Transport W hite Paper 2011, European Transport Research Review, 8(18): 1-14 (2016)

21. R. Danielis, E. Marcucci, A ttribute Cut-Offs in Freight Service Selection.

Transportation Research Part E, 43 (2007)

22. P. A rnold, P. D ominique, I. Thomas, M odelling a rail/road intermodal transportation system, Transportation Research Part E, 40: 255-270 (2003)

23. T. Y U, J.C. Richardson, A $n$ Exploratory Factor A nalysis and Reliability A nalysis of the Student Online L earning Readiness (SOL R) Instrument, The Online Learning Journal (OLJ), 19(5), 120-141 (2015)

24. H.Y. Kim, Statistical notes for clinical researchers: assessing normal distribution (2) using skewness and kurtosis, Open lecture on statistics, K orea U niversity College of Health (2013)

25. D. Garson, Testing of assumptions (2009), http://faculty.chass.ncsu.edu/garson/PA 765/assumpt.htm.

26. B.G. Tabachnick, L.S. Fidell, Using multivariate statistics (6th edition), B oston, M A : Pearson (2013)

27. M. Tavakol, R. Dennick, Post-examination analysis of objective tests, Med Teach., 33: 447-458 (2011) 
28. R. De V ellis, Scale development: theory and applications: theory and application, Thousand Okas, CA: Sage (2003)

29. A.G. Y ong, S., Pearce, A Beginner's Guide to Factor Analysis: Focusing on Exploratory Factor A nalysis, Tutorials in Quantitative Methods for Psychology, 9(2): 79-94, (2013)

30. B.G. Tabachnick, L.S. Fidell, Using Multivariate Statistics. 5th ed., N ew Y ork, NY, U.S.A : Pearson Education Inc (2007)

31. C.K.H. Hon, A.P.C Chan, M.C.H. Y am, Determining safety climate factors in the repair, maintenance, minor alteration, and addition sector of Hong K ong, Journal of Construction Engineering and Management, 139(5): 519-528 (2013)

32. J.F. Hair J r., W.C. Black, B.J. Babin, R.E. A nderson, R.L. Tatham, Multivariate data analysis, 7th Ed., Upper Saddle River, NJ: Prentice-Hall (2010) 